\title{
Direct inference of first-year sea ice thickness using broadband acoustic backscattering
}

Christopher Bassett, Andone C. Lavery, Anthony P. Lyons, Jeremy P. Wilkinson, and Ted Maksym

Citation: The Journal of the Acoustical Society of America 147, 824 (2020); doi: 10.1121/10.0000619

View online: https://doi.org/10.1121/10.0000619

View Table of Contents: https://asa.scitation.org/toc/jas/147/2

Published by the Acoustical Society of America

\section{ARTICLES YOU MAY BE INTERESTED IN}

Tracking of multiple surface vessels based on passive acoustic underwater arrays

The Journal of the Acoustical Society of America 147, EL87 (2020); https://doi.org/10.1121/10.0000598

Using a regional ocean model to understand the structure and variability of acoustic arrivals in Fram Strait

The Journal of the Acoustical Society of America 147, 1042 (2020); https://doi.org/10.1121/10.0000513

Exploring the promise of broadband fisheries echosounders for species discrimination with quantitative assessment of data processing effects

The Journal of the Acoustical Society of America 147, 411 (2020); https://doi.org/10.1121/10.0000594

Impacts of simulated infaunal activities on acoustic wave propagation in marine sediments

The Journal of the Acoustical Society of America 147, 812 (2020); https://doi.org/10.1121/10.0000558

A spatial correlation model for broadband surface noise

The Journal of the Acoustical Society of America 147, EL99 (2020); https://doi.org/10.1121/10.0000710

Time-warping in underwater acoustic waveguides

The Journal of the Acoustical Society of America 147, 898 (2020); https://doi.org/10.1121/10.0000693

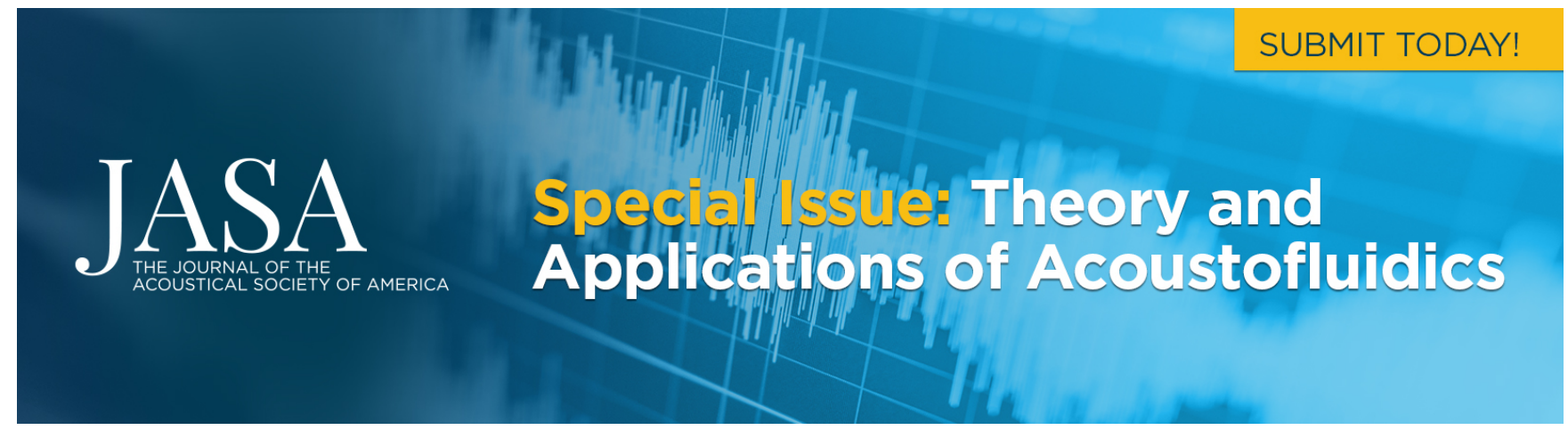




\title{
Direct inference of first-year sea ice thickness using broadband acoustic backscattering
}

\author{
Christopher Bassett, ${ }^{1, a)}$ Andone C. Lavery, ${ }^{2}$ Anthony P. Lyons, ${ }^{3}$ Jeremy P. Wilkinson, ${ }^{4}$ and Ted Maksym ${ }^{2}$ \\ ${ }^{1}$ Applied Physics Laboratory, University of Washington, 1013 Northeast 40th Street, Seattle, Washington 98105, USA \\ ${ }^{2}$ Department of Applied Ocean Physics and Engineering, Woods Hole Oceanographic Institution, Woods Hole, Massachusetts 02543, USA \\ ${ }^{3}$ University of New Hampshire, Center for Coastal and Ocean Mapping, 24 Colovos Road, Durham, New Hampshire 03824, USA \\ ${ }^{4}$ British Antarctic Survey, High Cross Madingley Road, Cambridge, CB3 OET, United Kingdom
}

\begin{abstract}
:
Accurate measurements of sea ice thickness are critical to better understand climate change, to provide situational awareness in ice-covered waters, and to reduce risks for communities that rely on sea ice. Nonetheless, remotely measuring the thickness of sea ice is difficult. The only regularly employed technique that accurately measures the full ice thickness involves drilling a hole through the ice. Other presently used methods are either embedded in or through the ice (e.g., ice mass balance buoys) or calculate thickness from indirect measurements (e.g., ice freeboard from altimetry; ice draft using sonars; total snow and ice thickness using electromagnetic techniques). Acoustic techniques, however, may provide an alternative approach to measure the total ice thickness. Here laboratory-grown sea ice thicknesses, estimated by inverting the time delay between echoes from the water-ice and ice-air interfaces, are compared to those measured using ice cores. A time-domain model capturing the dominant scattering mechanisms is developed to explore the viability of broadband acoustic techniques for measuring sea ice thickness, to compare with experimental measurements, and to investigate optimal frequencies for in situ applications. This approach decouples ice thickness estimates from water column properties and does not preclude ice draft measurements using the same data. (C) 2020 Acoustical Society of America. https://doi.org/10.1121/10.0000619

(Received 6 August 2019; revised 13 December 2019; accepted 3 January 2020; published online 6 February 2020)

[Editor: Thomas C. Weber]

Pages: 824-838
\end{abstract}

\section{INTRODUCTION}

Accurately monitoring sea ice is increasingly important given the rapid and extreme changes that are occurring in the Arctic. Indigenous communities have monitored Arctic sea ice thickness for centuries, but it has only been scientifically monitored on a semi-regular basis since the mid-twentieth century (Wadhams, 2000). Many early measurements were performed with ice augers, and this technique is still widely used today as a benchmark measurement. The advent of nuclear-powered submarines in the mid-1950s revolutionized under-ice operations permitting accurate measurements of ice draft (the thickness of ice below the water-line) with upwardlooking sonar (Lyons, 1961; Rothrock and Wensnahan, 2007). Over the years, many under-ice submarine missions have been performed, and it was the analysis of declassified ice draft data that first revealed that the summer sea ice in the Arctic was thinning at a rapid rate (approximately $40 \%$ since the 1970s) (Rothrock et al., 1999). More recently, this approach has been used in conjunction with satellite altimetry to infer decreases in Arctic ice mass (Kwok and Rothrock, 2009).

Satellite-mounted sensors, such as radar and laser altimeters (Kwok et al., 2007; Laxon et al., 2003), can also be used to estimate large-scale sea ice thickness at lower spatial resolutions. These techniques measure the height of the ice that is above the sea water (the freeboard), and the

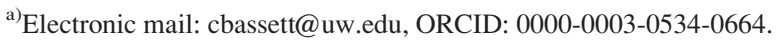

subsequent calculation of ice thickness requires a number of indirect assumptions (Forsberg and Skourup, 2005). Airborne altimeters face similar issues and both need open water regions to calibrate their calculated ice thickness data. Airborne electromagnetic soundings accurately measure the combined snow and ice thickness over level ice, but like altimeters, require an independent estimate of snow depth to determine ice thickness precisely (Eicken et al., 2014; Haas et al., 1997). Other sensors, such as airborne or ice mounted ground-penetrating radar, have potential to measure sea ice thickness, but only over certain ice thickness regimes, as these sensors are limited by the conductivity of sea ice (Galley et al., 2009).

Acoustic techniques have been used for high-accuracy, high-resolution mapping of ice draft (Wilkinson et al., 2007a) using sonars mounted on moving platforms (manned and unmanned underwater vehicles) or fixed platforms (subsea moorings) (Melling, 1998; Wilkinson et al., 2007b). Ice draft is determined from the acoustic range between the sonar and the underside of the ice, requiring an accurate estimate of the sound speed in the water and depth measurement on the vehicle (Williams et al., 2015) or mooring (Behrendt et al., 2013). Alternatively, accuracy may be improved using the range to the occasional open water between ice floes to provide a range reference. This method is more problematic during the winter months when open water regions can freeze over quickly, and can also have limited applicability in large regions of fast ice, such as the 
Canadian archipelago, where leads are rare (Wilkinson et al., 2007b).

Acoustic techniques have been limited to measuring ice draft and not total ice thickness. Upward-looking sonars do, however, have the potential to remotely measure full sea ice thickness from its top surface (snow-ice interface or air-ice interface) to the ice bottom (ice-water interface), yet relatively little has been published on this approach. This work seeks to address this potential by demonstrating, through experimental data and modeling, that estimating the full thickness of first-year ice in situ is feasible under some conditions. The development of an acoustic technique that fully penetrates the ice up to the ice-air interface, thereby measuring the full ice thickness, would complement ice draft measurements to better constrain depth and range estimates and potentially also provide the ice freeboard. Two important factors in determining the applicability and accuracy of this approach are understanding the frequency-dependent scattering and attenuation mechanisms for sea ice and the ability to accurately convert the time delay between the water-ice and ice-air interfaces to a distance.

Sea ice is morphologically complex, which facilitates the use of acoustic techniques that depend on penetration into the sea ice. The top portion of the ice may have a granular crystal structure (e.g., from freezing of frazil ice). Below this layer additional ice growth takes the form of congelation or columnar ice. Congelation ice is characterized by the transition to long, columnar crystals that comprise the majority ( $90 \%$ or more) of first-year ice pack (Weeks, 2010). An important characteristic of columnar ice is the transition zone from sea ice to sea water. This complex region at the bottom of the ice is commonly referred to as the skeletal layer. Critically, the skeletal layer results in a smooth transition from the acoustic properties (i.e., density and sound speed) of the seawater to the bulk properties of sea ice. At acoustic wavelengths on the order of the skeletal layer thickness or smaller, this gradual transition of acoustic properties facilitates the transmission of acoustic energy across the water-ice interface, acting as a high-pass filter. In contrast, the abrupt transition between the acoustic properties of sea ice and air means that nearly all of the acoustic energy is reflected at the upper ice interface. For older ice, the upper portion of the ice may contain a high density of bubbles, resulting in increased scattering.

Inference of the full thickness of sea ice using echoes from the water-ice and ice-air interfaces requires the conversion of the time delay between echoes to ice thickness. Previous investigations of sea ice have identified two dominant mechanisms that contribute to the observed acoustic scattering from the water-ice interface at normal incidence: (1) the transition in acoustical properties across the skeletal layer and (2) the physical structure of the skeletal layer itself. At high frequencies $(f>150 \mathrm{kHz})$ where the acoustic wavelengths are typically small compared to the thickness of the skeletal layer (i.e., $k a>1$, where $k=2 \pi / \lambda$ is the acoustic wavenumber and $a$ is a representative geometric scale related to the roughness), the physical structure (e.g., dendrite size) of the skeletal layer becomes important and scattering is less coherent (Bassett et al., 2016; Stanton et al., 1986). On the other hand, at $k a<1$, the scattering is less variable and specular reflections are dominated by the strong sound speed gradient across the skeletal layer (Garrison et al., 1991; Mourad and Williams, 1993; Wen et al., 1991; Williams et al., 1992; Winebrenner, 1992).

Accurately measuring the bulk acoustic properties of sea ice is difficult. Nonetheless, in situ measurements of the sound speed of growing sea ice have been used to calculate bulk sound speeds and formulate model sound speed profiles for sea ice (Wen et al., 1991; Williams et al., 1992; Winebrenner, 1992). These measurements and models suggest sound speed values approximately $20 \%$ higher than seawater $(\sim 1700 \mathrm{~m} / \mathrm{s})$ near the water-ice interface with rapid increases to roughly $3800 \mathrm{~m} / \mathrm{s}$ within a few centimeters during ice growth. Models for the reflection coefficient of sea ice applying these sound speed profiles and appropriate sea ice densities agree well with observations (Garrison et al., 1991; Williams et al., 1992; Winebrenner, 1992).

As with the water-ice interface, the interior of the ice is morphologically complex and acoustic backscattering is expected to vary strongly with frequency. Light et al. (2003) used ice cores from shorefast ice near Point Barrow, Alaska, to quantify the size distribution and density of brine channels, bubbles, and other impurities that affect the optical properties of sea ice. This work showed higher bubble densities (approximately 1.3 bubbles $/ \mathrm{mm}^{3}$ ) than had been previously reported (Gavrilo and Gaitskhoki, 1971; Grenfell, 1983). These bubbles, which followed a power-law distribution with radii from 0.004 to $0.1 \mathrm{~mm}$, were noted to be located primarily within brine inclusions. At atmospheric pressure, acoustic resonance of bubbles occurs when $k a=0.0136$, where $a$ is the radius of the bubble (Medwin and Clay, 1998). Bubble sizes reported by Light et al. (2003) would result in resonance over a broad range of frequencies $(30 \mathrm{kHz}<f<450 \mathrm{kHz})$ and could make considerable contributions to backscatter from and attenuation through sea ice.

Brine tubes and pockets are also important features of sea ice (Weeks, 2010) and occupy considerably more volume than bubbles in first-year ice Light et al. (2003). The geometry of these brine inclusions is highly variable but the larger dimension of elongated inclusions is generally oriented perpendicular to the water-ice interface. Maximum characteristic diameters of brine inclusions reported in Light et al. (2003) were less than $0.25 \mathrm{~mm}$ although smaller densities of larger brine inclusions (diameters up to $1 \mathrm{~mm}$ ) are also present within ice (Perovich and Gow, 1991, 1996). When $k a \ll 1$ the acoustic wavelength is much larger than the characteristic length scale of the scatterer and, as a result, the backscattering cross-section decreases rapidly with decreasing frequency $\left(f^{-4}\right)$. Therefore, while backscatter from brine inclusions may be relatively unimportant at normal incidence and at frequencies less than $200 \mathrm{kHz}$ (the frequency range considered in this paper), their contribution to acoustic backscatter at higher frequencies and oblique 
incidence angles may be considerable. The large bubbles often found in the upper portion of sea ice that has survived a summer melt season (Perovich and Gow, 1996) could result in significant scattering and limit acoustic penetration through this type of ice.

Another factor limiting the ability of acoustic techniques to penetrate through sea ice for the purpose of inferring thickness is the acoustic attenuation, which includes both intrinsic absorption and scattering losses, though little has been published on this subject. In situ measurements of acoustic attenuation along a horizontal path in second-year sea ice from 10 to $500 \mathrm{kHz}$ were performed by Langleben (1969). Empirically derived attenuation rates for sea ice were calculated as the sum of two frequency-dependent terms: the first followed a linear-frequency dependence and was related to frictional losses, and the second term followed a $f^{4}$ dependence and was attributed to scattering at the grain boundaries and inter-granular differences in elastic properties. Observed attenuation was highly dependent on frequency with values as low than $1 \mathrm{~dB} / \mathrm{m}$ at $10 \mathrm{kHz}$ to greater than $35 \mathrm{~dB} / \mathrm{m}$ at $500 \mathrm{kHz}$. Wen et al. (1991) present an empirical, temperature-dependent attenuation equation for first-year sea ice derived from vertical transmissions that follow a linear-frequency dependence with an added temperature term that to account for changes in the ice at higher temperatures. The differences between attenuation rates in these studies vary by a factor of two or more with Wen et al. (1991) reporting higher attenuation rates. While the skeletal layer facilitates the transmission of energy from the water into the ice, it also absorbs energy. Stanton et al. (1986) hypothesized that the attenuation was highest in the skeletal layer due to the high porosity. This hypothesis was later confirmed by measurements that suggested that the attenuation in the skeletal layer alone was between $2.5 \mathrm{~dB}$ at $37 \mathrm{kHz}$ (Wen et al., 1991 ) to $2-5 \mathrm{~dB} / \mathrm{cm}$ at $92 \mathrm{kHz}$ (Williams et al., 1992). Note these values are presented with different units whereby one represents losses integrated over the entire skeletal layer and the other values are presented per unit length.

This work investigates the feasibility of directly inferring the full ice thickness using broadband pulses combined with matched-filter, also referred to as pulse-compression, processing techniques (Chu and Stanton, 1998; Stanton, 2012; Turin, 1960). This approach has distinct advantages over narrowband measurements performed to date. First, the temporal resolution is proportional to the inverse of the bandwidth of the transmitted signal rather than being constrained by the pulse duration. Thus, pulse compression techniques can be used to considerably improve the tempo$\mathrm{ral} / \mathrm{spatial}$ resolution of the measurements, an important factor due to the high sound speed in ice. This allows relatively low frequencies, which attenuate less rapidly, to be used while still achieving high spatial resolution. Additional improvements in the signal-to-noise ratio (SNR) that are proportional to the product of the pulse duration and transmitted bandwidth also result from pulse compression processing, and additional broadband signal processing approaches can also improve the ability to detect closely spaced echoes (Chu and Stanton, 1998; Lavery et al., 2017).

Acoustic backscatter measurements $(75-130 \mathrm{kHz})$ are presented for laboratory-grown sea ice up to $80 \mathrm{~cm}$ thick. Inversions for the ice thickness based on the time delays between echoes from the water-ice and ice-air interface are compared to measurements from ice cores. These inversions are based on previously published properties of growing sea ice. In addition, a model is presented that accounts for the likely dominant physical processes that affect acoustic backscattering from the water-ice interface, bubbles within the ice, and the ice-air interface. This model is used to investigate the trade-off between parameters that could be used to replicate such an approach in situ. Additional remarks focus on the practical considerations related to field applications of the discussed techniques.

\section{METHODS}

All measurements were taken as part of an experiment investigating high-frequency backscattering from controlled releases of crude oil under laboratory-grown sea ice. The experiments were performed at the Ice Engineering Facility Testing Basin at the Cold Regions Research and Environmental Laboratory (CRREL) in Hanover, NH, between October 23, 2014, and January 23, 2015. Additional details about the facilities, experiment, and instrumentation can be found in Bassett et al. (2016) and Pegau et al. (2017).

The tank (36.6 m long, $9.1 \mathrm{~m}$ wide, and $2.4 \mathrm{~m}$ deep) was filled with water and sodium chloride to achieve a starting salinity of approximately 27 PSU. Salt rejection and drainage during the ice growth period resulted in a final salinity of 37.4 PSU. The tank was equipped with two thermistor chains with sensors spaced at $10 \mathrm{~cm}$ intervals to measure temperature profiles within the water and ice. Conductivity, temperature, and depth (CTD) casts were performed throughout the experiment. With the exception of periods in which air temperatures increased due to a weather-related power outage or when individuals were in the room conducting experiments, the ambient temperature was maintained at approximately $-23{ }^{\circ} \mathrm{C}$. During the relatively warm periods, maximum air temperatures were maintained at or below $-8{ }^{\circ} \mathrm{C}$.

Acoustic backscattering measurements at normal incidence were obtained using two separate systems. The first system was used primarily for measurements of oil-under ice, but ice backscattering measurements were obtained for ice thicknesses greater than $30 \mathrm{~cm}$. Another system was used to measure backscattering from ice alone but was limited to ice thicknesses less than $60 \mathrm{~cm}$. The use of two systems and data sets does not reflect the limitations of the methods or systems. Instead, it reflects choices made while pursuing the goals of the main project, the detection of oil under sea ice. Combining these measurements was necessary to obtain measurements with ice thicknesses from initial growth to greater than $80 \mathrm{~cm}$ (as determined from ice cores).

The first system, hereafter referred to as System 1, used a rail/cart assembly positioned along the axis of the tank. 
The cart was driven by an underwater servomotor and a laptop computer, which were used to move the cart at a constant speed or position it with centimeter-scale precision (Pegau et al., 2016). All backscattering measurements of the ice were obtained outside of the oil containment skirts that had been placed in the tank. System 1 measured broadband acoustic backscattering with a modified Edgetech sidescan sonar system (Bassett et al., 2016; Lavery et al., 2010) and custom Airmar Technology Corporation (35 Meadowbrook Drive, Milford, NH) broadband transducers operated in a monostatic configuration. The transducer used in this analysis transmitted a $75-130 \mathrm{kHz}$ linear frequency modulated (LFM) chirp. The transmit power was held constant throughout the experiment. One notable limitation, which would not be restrictive in situ, was that the pressure release water-air interface was used for calibration prior to ice formation. This required that the received signal was not saturated at a short range $(2.2 \mathrm{~m})$, thereby limiting the amount of power that could be transmitted.

System 2 relied on a bi-static configuration with two normal incidence transducers located adjacent to each other with beam footprints that overlapped at the ranges of interest. Both transducers were mounted on a plate that was fixed to a $1.3 \mathrm{~m}$ horizontal pole. This system was rotated using a vertical pole that extended through a polyvinyl chloride (PVC) pipe at the ice surface that was equipped with a resistive heater to prevent the interior from freezing. A summary of the power electronics used for measurements are described in Bassett et al. (2015). The transducers, transmitted bandwidth, signal tapers, and pulse durations were the same as for System $1(75-130 \mathrm{kHz})$. When taking measurements, the system was rotated in 6-degree increments over 180 degrees to obtain backscattering statistics. The data presented here are derived from data furthest from the tank wall (approximately $2 \mathrm{~m}$ ). Raw time series data were sampled at $5 \mathrm{MHz}$ using a custom LabVIEW script.

Data from both systems are presented as the log-space envelope-squared of pulse-compressed data (Chu and Stanton, 1998; Stanton, 2012; Turin, 1960) time series, which is obtained through the convolution of the analytic form of the received voltage time series with the analytic "replica" transmit voltage time series. The replica time series is calculated through scalar multiplication of the LFM signal with a Hann (i.e., a raised-cosine) window.

\section{INFERENCE OF ICE THICKNESS}

Ice thicknesses are inferred from normal incidence data by measuring the time delay between the echoes from the water-ice interface and the ice-air interface. This time delay is related to the sound speed profile in the ice. In this case, the sound speed profile is modeled based on previously published, empirically derived profiles according to

$$
c_{\text {ice }}(z)=\left(2 c_{a}-c_{1}\right)+\left(c_{1}-c_{a}\right)\left[1+\tanh \left(\delta_{z} z\right)\right],
$$

where $c_{1}(3800 \mathrm{~m} / \mathrm{s})$ is the bulk sound speed of the ice, $c_{a}$ $(1700 \mathrm{~m} / \mathrm{s})$ is the sound speed of the ice at the water-ice interface, $z$ is the distance from the water-ice interface in meters, and $\delta_{z}$ is a term that determines the gradient within the skeletal layer (Winebrenner, 1992). When applying the sound speed profile to the model and data $\delta_{z}=45 \mathrm{~m}^{-1}$ is used. This parameterization results in a sound speed profile reaching the bulk ice sound speed approximately $5 \mathrm{~cm}$ from the water-ice interface. Williams et al. (1992) noted that this sound speed profile was not consistent with their physical measurements of sea ice, which suggested a thinner skeletal layer, but is consistent with acoustic data from which it was derived. Likewise, ice cores and micro-CT scans from the experiment described here showed the skeletal layer had a thickness of approximately $2 \mathrm{~cm}$ following the initial stages of ice growth (Courville et al., 2017; Pegau et al., 2016). Bulk salinities measured from the cores ranged from 5 to 9 parts per thousand throughout the experiment with maximum salinities near the water-ice interface. Thermistor chains frozen into the ice generally showed linear temperature profiles. The bulk salinity and temperature profiles are consistent with ice properties obtained in previous in situ acoustics experiments (e.g., Garrison et al., 1991). Regardless of the sound speed profile, values of $\delta_{z}$ that correspond to reasonable skeletal layer thicknesses result in similar amplitude reflection coefficients in the frequency ranges modeled here. The impact on the time delay between the water-ice and ice-air interfaces for ice thickness greater than $20 \mathrm{~cm}$ is also small.

Given an arbitrary sound speed profile and ice thickness, the time delay between echoes from the water-ice and ice-air interfaces is described by

$$
\Delta t=2 \int_{0}^{h_{\text {ice }}} \frac{1}{c_{\text {ice }}(z)} d z
$$

where $h_{\text {ice }}$ is the ice thickness, $c_{\text {ice }}(z)$ is the sound speed profile of the ice, $z$ is the distance from the water-ice interface, and the factor of two accounts for the two-way travel. For numerical integration of Eq. (1), the sound speed profile is discretized to $0.05 \mathrm{~mm}$, which is much smaller than the wavelengths in this study. The inferred ice thickness is then calculated by minimizing the difference between the observed time delay and solutions to Eq. (2) calculated for ice thickness ranges from 3 to $100 \mathrm{~cm}$ in $1 \mathrm{~mm}$ increments. For comparison, bulk sound speeds are calculated using Williams and Francois [1992, Eq. (25)], which is a general form that calculates a representative bulk sound speed given surface temperatures and the ice thickness. This alternative bulk sound speed for the ice based on Biot theory (Biot, 1956a,b) is used for comparing inferred ice thicknesses that would result from the application of Eq. (1) to Williams and Francois (1992). The comparisons are made for air temperatures of $-20,-10$, and $0^{\circ} \mathrm{C}$.

To compare the performance of the inferred ice thickness with ice core measurements a residual is defined as

$$
h_{\mathrm{res}}=h_{\mathrm{inf}}-\left(h_{\mathrm{draft}}+h_{\mathrm{free}}\right) \text {, }
$$

where $h_{\text {inf }}$ is the total inferred thickness, $h_{\text {draft }}$ is the ice draft measured using the time delay to the ice-water interface and 


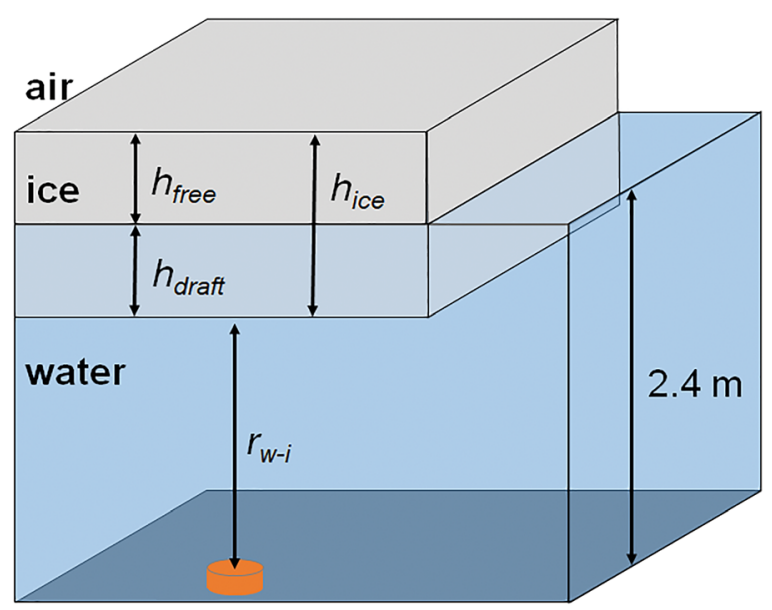

FIG. 1. (Color online) A cartoon showing the relationship between the total ice thickness, freeboard, and draft. The depth label is specific to the tank measurements.

sound speed measurements, and $h_{\text {free }}$ is the measured freeboard from ice cores (Fig. 1). Ice drafts are calculated using the differences between the time delay to the water-ice interface and the free surface prior to ice formation coupled with the sound speed of the water as determined using the CTD casts (Chen and Millero, 1977). Residuals are calculated for all measurements where ice core thicknesses and freeboard are available in addition to the acoustic measurements. Mean and standard deviations of $h_{\text {res }}$ are reported in Sec. V.

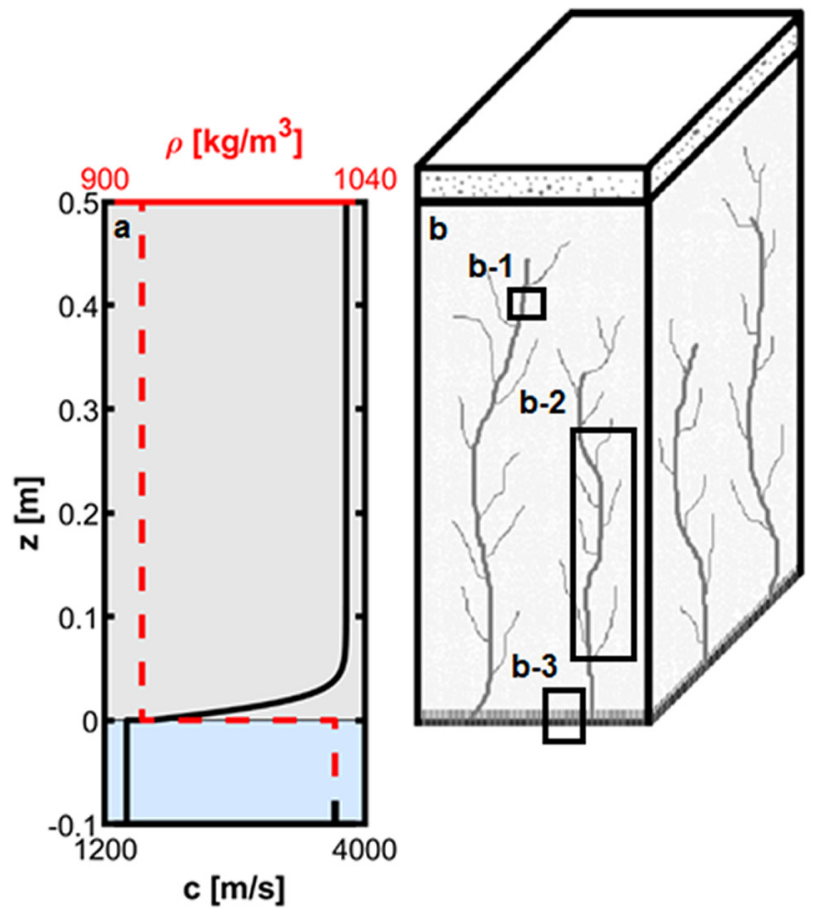

\section{MODELING}

A temporal domain model for the backscattering from the interfaces and ice volume was developed for comparisons with tank measurements and to predict backscattering for other ice thicknesses and operating parameters. Model results combine the reflection from the water-ice interface, attenuation within the ice, volume scattering from bubbles within the ice, and the reflection from the ice-air interface. The steps for modeling the backscattering are broken into sections related to the creation and processing of the transmit signals, the backscattering from the interfaces and ice volume, and the construction of a pulse compressed time series for different ice thicknesses. To illustrate the complex structure of the ice, Fig. 2 shows key ice features, which are described in detail Secs. IV A-IV D.

\section{A. Transmit signals}

An LFM signal, $x(t)$, is generated in the temporal domain. This signal is described by

$$
x(t)=\sin \left(2 \pi f_{0} t+\frac{\pi\left(f_{1}-f_{0}\right) t^{2}}{\tau_{t}}\right) \text { for } 0 \leq t \leq \tau_{t},
$$

where $f_{0}$, and $f_{1}$, and $\tau_{t}$ and are the initial frequency, final frequency, and pulse duration, respectively. A sampling rate of $500 \mathrm{kHz}$ is used to create $x(t)$. The Hann-tapered transmit signal is defined as

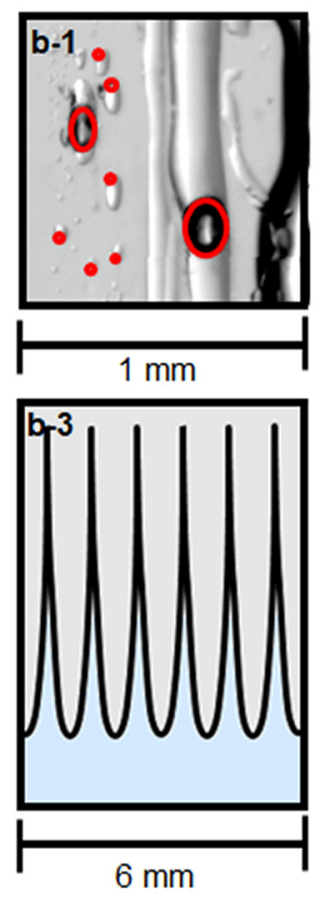

FIG. 2. (Color online) A collection of images showing the complexity of first-year sea ice. (a) Sound speed and density profiles based on the literature and used in model parameterization. (b) A cartoon of first-year ice with a layer of snow on top. Brine channels are shown within the ice. (b-1) An image of bubbles, highlighted in red, within brine pockets and channels. Image credit: Bonnie Light (Light et al., 2003). (b-2) Picture of an ice core showing a vertically oriented brine channel. Image credit: Ken Golden. (b-3) A cartoon showing the approximate geometry of the skeletal layer at the water-ice interface (see Schwarz and Weeks, 1979, for additional details). 


$$
x_{w}(t)=x(t) \sin ^{2}\left(\frac{\pi t}{\tau_{t}}\right) \quad \text { for } 0 \leq t \leq \tau_{t},
$$

where the tapered time series, $x_{w}(t)$, is obtained by the scalar multiplication of the indices of the transmit signal time series and the window function. Chu and Stanton (1998) and Lavery et al. (2017) show relevant examples of different tapers, their autocorrelations, and their frequency responses. An analytic signal representing the $x_{w}(t)$ time series, $\hat{x}_{w}(t)$, is used in the model. Interface reflections, bubble scattering, and attenuation are modeled in the frequency domain. Therefore, the time series $\hat{x}_{w}(t)$ is transformed to the frequency-domain, $\hat{X}_{w}(f)$, using a fast Fourier transform of the transmit signal.

For comparisons to the laboratory data, the transmit signal parameters in the model are chosen to match the data. That is, a $256 \mu \mathrm{s}, 75-130 \mathrm{kHz}$ LFM signal with a Hann taper is used. The transmit signal parameters used for predicting the temporal domain signals from ice thicknesses are included in Table I and are based on typical parameters for commercially available broadband echosounders.

\section{B. Interface reflections}

Two sources of reflections, the water-ice and ice-air interfaces, are considered and denoted by the subscripts ${ }_{w-i}$ and ${ }_{i-a}$, respectively. Additional volume backscattering from bubbles within the ice is denoted by the subscript ${ }_{b u b}$. Each of these terms is modeled by modifying the Fourier transform of the tapered transmit signal by the terms accounting for the frequency-dependent scattering and absorption.

At the water-ice interface the frequency-dependent reflection coefficient is driven by the sound speed profile [Eq. (1)] and density of the ice. Measured densities during the experiment were approximately $900 \mathrm{~kg} / \mathrm{m}^{3}$ (Pegau et al., 2016). For the predictions shown here, a higher value that is consistent with typical in situ observations, $920 \mathrm{~kg} / \mathrm{m}^{3}$ (Timco and Frederking, 1996), is used. The difference in sound speed across the interface is much greater than the change in density, therefore the application of any reasonable density value will not have a large impact on the reflection

TABLE I. Modeled parameters for the Hann-tapered transmit signals. The beamwidth $\left(\theta_{b w}\right)$ and volumes in ice are shown at the nominal frequency $\left(f_{\text {nom }}\right)$. The approximate range resolution, $\Delta r$, is based on the bandwidth, accounts for the loss of bandwidth due to the taper, and uses a bulk sound speed in ice of $3800 \mathrm{~m} / \mathrm{s}$. Beam volume is calculated according to $V=\left(\pi D^{2} / 4\right) \Delta r$, where $D$ is the diameter of the beam at the water-ice interface, for a range of $20 \mathrm{~m}$. While all of the signal parameters were used for predictions, only the $f_{\text {nom }}=100 \mathrm{kHz}$ signals are associated with laboratory measurements.

\begin{tabular}{lcccc}
\hline \hline$f_{\text {nom }}(\mathrm{kHz})$ & 38 & 70 & 100 & 120 \\
\hline$f(\mathrm{kHz})$ & $34-45$ & $45-90$ & $75-130$ & $95-155$ \\
$\tau_{t}(\mu \mathrm{s})$ & 1000 & 1000 & 256 & 1000 \\
$\Delta r(\mathrm{~cm})$ & 31 & 8 & 6 & 6 \\
$\theta_{b w}\left({ }^{\circ}\right)$ & 7.0 & 7.0 & 9.6 & 7.0 \\
Vol. $\left(\mathrm{m}^{3}\right)$ & 1.45 & 0.37 & - & 0.37 \\
\hline \hline
\end{tabular}

J. Acoust. Soc. Am. 147 (2), February 2020 coefficient. The amplitude reflection coefficient is calculated numerically (Brekhovskikh and Godin, 1990) by discretizing the domain to $\lambda_{200} / 20$, where $\lambda_{200}$ is the acoustic wavelength is the wavelength in the water at $200 \mathrm{kHz}$, and the sound speed and density of the water are $c_{w}=1436 \mathrm{~m} / \mathrm{s}$ and $\rho_{w}=1027$ $\mathrm{kg} / \mathrm{m}^{3}$, respectively. Figure 3(a) shows the reflection coefficient from the water-ice interface as a function of frequency, which agrees well with the experimental results presented in Williams et al. (1992).

At the ice-air interface, the reflection coefficient is assumed to be $\mathcal{R}_{i-a}=-1$ at all frequencies due to the large acoustic impedance mismatch at the pressure release surface between the sea ice and air. Any potential contribution from an ice-snow interface is also neglected assuming large density and sound speed differences between the media. In practice, this impedance mismatch is dependent on the condition of the snow. Previously reported properties (Capelli et al., 2016, and references therein) suggest that for a range of snow conditions $\left|\mathcal{R}_{i-a}\right|>0.6$. Therefore, an ice-snow interface is acoustically similar to an ice-air interface.

At normal incidence, the amplitude of reflected pressure from an acoustically smooth interface (i.e., root-meansquare roughness much less than the acoustic wavelength), ignoring losses (e.g., attenuation) is described by

$$
P_{\text {scat }, \mathcal{R}}=\frac{p_{o} r_{o} \mathcal{R}}{2 r}
$$

where $\mathcal{R}$ is the amplitude reflection coefficient, $r$ is the range to the interface from the source/receiver, $r_{o}$ is the reference range for the source, and $p_{o}$ is the reference pressure. The reference pressure and range are arbitrarily set to $p_{o}$ $=1 \mathrm{~Pa}$ and $r_{o}=1 \mathrm{~m}$. Depending on their size and the incident beam pattern, reflections may exhibit interference patterns attributed to differences in phase across the ensonified surface (Medwin and Clay, 1998). Areas, rings in the case
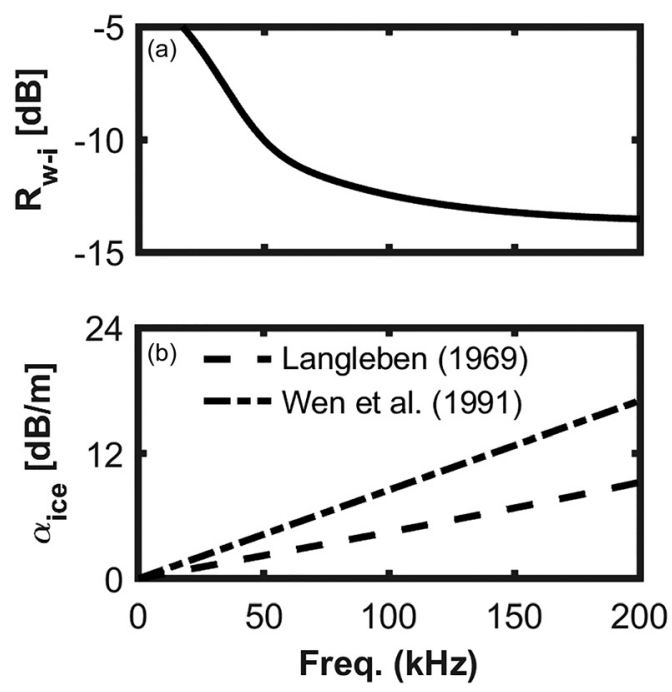

FIG. 3. (a) The amplitude reflection coefficient for the water-ice interface as a function of frequency. (b) Two functions for the attenuation in sea ice as a function of frequency. The Wen et al. (1991) model is applied because the measurements were made of first-year sea ice at normal incidence. 
of a circular transducer, where the phase has the same sign, are referred to as Fresnel zones. The potential impact of Fresnel zones was considered by modeling the spherically spreading wave with the transducer beam patterns to verify that the assumptions inherent in Eq. (6) were valid. Fresnel zones had a negligible impact at ranges greater than $10 \mathrm{~m}$, thus Eq. (6) is used to model interface reflections. Relevant losses include attenuation in water for reflections from the water-ice interface. For the ice-air interface, losses include attenuation in the water and ice, in the skeletal layer, and due to refraction in the ice.

In the model, both the range to the ice and its thickness, $h_{\text {ice}}$, are prescribed. Therefore, additional modifications to the scattered pressure curves are made to account for attenuation within the ice. As a function of frequency and temperature the attenuation, following Wen et al. (1991), is described by

$$
\alpha_{i}(f)=0.19 f\left(\frac{-6}{T}\right)^{(2 / 3)},
$$

where $\alpha_{i}$ is the attenuation rate in $\mathrm{dB} / \mathrm{m}, f$ is the frequency in $\mathrm{kHz}$, and $T$ is the temperature in ${ }^{\circ} \mathrm{C}$. The attenuation as a function of frequency for both Langleben (1969) and Wen et al. (1991), is shown in Fig. 3(b) for $-20^{\circ} \mathrm{C}$.

In previously published measurements of highfrequency acoustic attenuation from sea ice, no information regarding bubble densities was presented. Underpinning the use of previously published attenuation rates, particularly given the lack of terms accounting for additional absorption by bubbles, is the assumption that the measurements discussed in Wen et al. (1991) were taken in ice with similar bubble densities and sizes. The validity of this assumption is questionable but to our knowledge, the literature contains no measurements to further constrain the problem.

Interface reflection terms are calculated by modifying Eq. (6) to account for relevant losses. The backscattered pressure at the receiver from the water-ice interface is described by

$$
P_{w-i}(f)=\frac{p_{o} r_{o} \mathcal{R}_{w-i}}{2 r_{w-i}} 10^{\left(-2 \alpha_{w} r_{w-i}\right) / 20}
$$

where $\alpha_{w}$ is the attenuation in $\mathrm{dB} / \mathrm{m}$ as a function of frequency in water (Francois and Garrison, 1982a,b), $\mathcal{R}_{w-i}$ is the reflection coefficient at the water-ice interface, and $r_{w-i}$ is the range to the interface. The backscattered pressure at the receiver from the ice-air interface is

$$
P_{i-a}(f)=\frac{p_{o} r_{o} \mathcal{R}_{a}\left(1-\mathcal{R}_{w-i}^{2}\right)}{2\left(r_{w-i}+N h_{\text {ice }}\right)} 10^{\left[-2\left(h_{\text {ice }} \alpha_{i}+\alpha_{s}+r_{w-i} \alpha_{w}\right)\right] / 20},
$$

where $\mathcal{R}_{a}=-1$ and $N$ is the index of refraction $\left(c_{\text {ice }} / c_{w}\right)$, which accounts for the defocusing of the spherically spreading wave caused by the change sound speed at the interface. A derivation of this term is supplied as supplementary material. ${ }^{1}$ Equation (9) describes the amplitude reflection using an from the ice-air interface minus the total losses from attenuation in the skeletal layer $\left(\alpha_{s}\right)$, and the reflections from the water-ice $\left(\mathcal{R}_{w-i}=-\mathcal{R}_{i-w}\right)$ and ice-air interfaces. Accounting for the index of refraction results in relatively small corrections to the reflection pressure from the ice-air interface $(<1 \mathrm{~dB})$ when the ratio $h_{\text {ice }} / r_{w-i}>0.1$. The $\alpha_{s}$ parameter is poorly constrained, but measurements (Williams et al., 1992) suggest values from 2 to $5 \mathrm{~dB} / \mathrm{cm}$ within the skeletal layer for signals at $92 \mathrm{kHz}$ are appropriate. This attenuation is likely strongly dependent on frequency but cannot be further constrained without additional information. Here these are modeled independently of the thickness of the skeletal layer. A total of $5 \mathrm{~dB}$ (each direction) produced a good agreement with the tank measurements. As with our use of the $\alpha_{i}$ values found in Wen et al. (1991), the use of the loss values in the skeletal layer which are at the high end of expected values ensures that attenuation rates will not be a limiting factor for this application.

\section{Volume backscattering}

The total volume backscatter from the ice is determined by calculating the incoherent sum of backscattering crosssections from all bubbles within the ensonified volume. First, a population of bubbles to model is created according to the power-law distribution described in Light et al. (2003). All bubbles are assumed to be within the brine channels and to be sufficiently small compared to the brine channel cross-section that they are not constrained by the surrounding ice. The inclusion of bubbles present within the ice, as opposed to the brine channels, would require a different scattering model and is not considered. Given the large number of bubbles in a $1 \mathrm{~m}^{3}$ volume given a density of 1.3 per $\mathrm{mm}^{3}$, a smaller number of bubbles corresponding to a sub-sampled volume $\left(V_{\text {sub }}\right)$ of $47 \mathrm{~cm}^{3}$ are randomly selected from the distribution for modeling. Bubbles in this distribution have radii from 4 to $100 \mu \mathrm{m}$ with larger densities being associated with smaller bubbles. The differential backscattering cross-section for an individual bubble is calculated according to

$$
\sigma_{b s}(f)=\frac{a^{2}}{\left[\left(f_{r} / f\right)^{2}-1\right]^{2}+\delta^{2}(f)},
$$

where $a$ is the bubble radius; $f_{r}$ is the resonance frequency; and $\delta$ is a coefficient accounting for damping from radiation, thermal, and viscous effects (Medwin and Clay, 1998; Vagle and Farmer, 1992). Numerous gas and water properties are required to solve for the damping coefficient. Due to the high salinity and low temperatures commonly used equations for seawater properties are not applicable. Given that the bubbles are located within the brine inclusions, relevant properties were calculated at $0^{\circ}$ and a salinity of 80 PSU according to Sharqawy et al. (2010) and Nayar et al. (2016), which calculated the thermophysical properties of water over a greater range of salinity values. Air properties were calculated at $0{ }^{\circ} \mathrm{C}$ and atmospheric pressure. Target 
strength (TS) curves, defined as TS $=10 \log _{10}\left(\sigma_{b s}\right)$, for individual bubbles are included in Fig. 4(a). Measurements of attenuation in the ice are assumed to account for all losses so the absorption and extinction cross-sections are not calculated or included.

Neglecting multiple scattering, the volume backscattering coefficient for the bubbles as a function of frequency is

$$
\mathrm{s}_{\mathrm{v}}(f)=\frac{1}{V_{\text {sub }}} \sum_{j=1}^{n_{\text {bub }, \text { sub }}} \sigma_{b s, j}
$$

where $n_{\text {bub.sub }}$ is the number of bubbles, $j$ is an index corresponding to a given bubble from the modeled distribution, and the subscript sub denotes that the calculation is for a subsampled volume $V_{\text {sub }}$. Figure 4(b) shows the logarithmic volume backscattering coefficient for the modeled bubble size distribution.

To facilitate the combined presentation of terms associated with both interface reflections and bubbles the volume backscattering is converted to pressure. The remaining terms required to solve for the scattered pressure for volume scattering, ignoring the effects from the interface scattering from the water-ice interface and attenuation, are described in linear units by

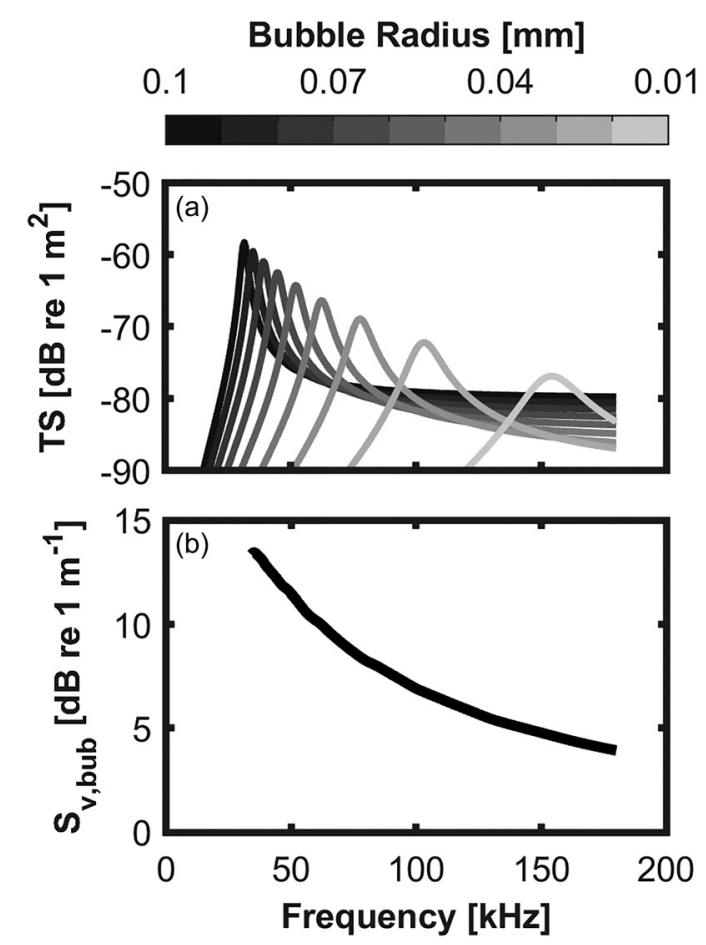

FIG. 4. (a) Models of the target strengths of individual bubbles at atmospheric pressure (Medwin and Clay, 1998; Vagle and Farmer, 1992). The modeled bubble radii are consistent with those reported to be present in first-year sea ice (Light et al., 2003) and are shown to be resonant across a wide range of frequencies. (b) The volume backscattering from bubbles where $S_{v}$ is the logarithmic form of $s_{v}$. This assumes a total bubble density of 1.3 bubbles $/ \mathrm{mm}^{3}$ using the power law distribution from Light et al. (2003) from 0.004 to $0.1 \mathrm{~mm}$. The modeled properties of for brine, calculated according to Sharqawy et al. (2010), are $\mu=0.0021 \mathrm{cP}, \tau=77.9 \mathrm{mN} /$ $\mathrm{m}, C_{p a}=1004 \mathrm{~J} / \mathrm{kg} \mathrm{K}, K_{a}=0.24 \mathrm{~W} / \mathrm{m} \mathrm{K}, \gamma=1.4, \rho_{w}=1064 \mathrm{~kg} / \mathrm{m}^{3}$, and $\rho_{a}=1.30 \mathrm{~kg} / \mathrm{m}^{3}$.

$$
P_{\text {scat }, \text { vol }}^{2}(f)=\frac{p_{o}^{2} r_{o}^{2} s_{v} V}{r^{4}}
$$

where $V$ is the sampled volume and is approximated by

$$
V(f)=\pi \Delta r\left[r_{w-i} \tan \left(\frac{\theta_{b w}}{2}\right)\right]^{2}\left(\frac{f}{f_{n o m}}\right)^{2},
$$

$\Delta r$ is the range resolution of the pulse compressed signal in the ice, and $\theta_{b w}$ is the beamwidth at the nominal frequency (Table I). The ratio of the frequency to the nominal frequency accounts for the changes in beam volume that occur for a fixed geometry transducer transmitting a broadband pulse (Medwin and Clay, 1998). These terms assume that the bubbles are distributed randomly throughout the volume and, as a result, the amplitude of the backscattering is offset by the relative volume of the beam at the different frequencies.

The contribution from bubbles within the ensonified volume of the ice, after the losses described in Sec. IV B is described by

$$
P_{b u b}(f)=\frac{p_{o} r_{o}\left(1-\mathcal{R}_{\mathrm{w}-\mathrm{i}}^{2}\right)}{\left(r_{w-i}+N r_{i}\right)^{2}} \sqrt{s_{v} V} 10^{\left[-2\left(r_{i} \alpha_{i}+\alpha_{s}+r_{w-i} \alpha_{w}\right)\right] / 20},
$$

where $r_{i}$ is the vertical distance within the ice from the water-ice interface. Unlike the interface terms, $P_{b u b}$ is solved at every range included in the modeled ice thickness.

\section{Modeled time series}

The temporal domain model replicates pulse compression processing through the convolution of the tapered transmit signal with a replicate signal modified by the frequencydependent, modeled backscattering. Modifications to the modeled, transmit waveform are applied as filters in the frequency domain for the three sources of scattering according to

$$
\hat{X}_{j}(f)=\hat{X}_{w}(f) * P_{j}(f),
$$

where the index $j$ denotes the scattering source and $P_{j}$ is the modeled backscattering for either the water-ice interface, the ice-air interface, or the bubbles after accounting for relevant losses such as reflection coefficients and attenuation. These spectra are used to create a time series for the echoes. First, modeled spectra for the interface reflections and contributions from bubbles are converted back to the time domain by taking the inverse Fourier transforms of $\hat{X}_{\mathrm{w}-\mathrm{i}}(f), \hat{X}_{\mathrm{bub}}(f)$, and $\hat{X}_{\mathrm{i}-\mathrm{a}}(f)$ to get the analytic signals $\hat{x}_{\mathrm{w}-\mathrm{i}}(t), \hat{x}_{\text {bub }}(t)$, and $\hat{x}_{\mathrm{i}-\mathrm{a}}(t)$. Pulse compressed time series for the contributions to the total backscattering are calculated by

$$
\hat{x}_{\mathrm{pc}, \mathrm{j}}(t)=\frac{\hat{x}_{j}(t) \otimes x_{w}^{*}(-t)}{\left\|\hat{x}_{w}(t)\right\|^{2}},
$$

where $j$ is an index that corresponds to the backscattering source, $x_{w}^{*}(-t)$ is the time-reversed complex conjugate of the tapered transmit signal, and $\otimes$ represents a convolution. 
A time series is produced through the convolution of the frequency-dependent scattering from each interface with a time series representing the location of the scatterers, $g_{j}(t)$. This time series is described by

$$
g_{j}(t)= \begin{cases}0 & \text { if } t<t_{w-i} \\ 1 & \text { if } t=t_{w-i} \\ \frac{U([0.5,1.5])}{b} & \text { if } t_{w-i}<t<t_{i-a} \\ 1 & \text { if } t=t_{i-a} \\ 0 & \text { if } t>t_{i-a},\end{cases}
$$

where $b$ is a constant and $U([0.5,1.5])$ describes a random value sampled from a uniform distribution between 0.5 and 1.5 to introduce small amplitude modulations to the portion of the backscattering dominated by the bubbles. The constant $b$ is a normalization factor that accounts for the fact that the range resolution contains multiple points in $\hat{x}(t)$ so $g_{j}(t)$ must be scaled to account for the equivalent volume associated with each point in the time series. Therefore, $b=f_{s} \Delta r / c_{\text {ice }}$, where $f_{s}$ is the sampling rate of $\hat{x}_{\mathrm{pc}, \mathrm{j}}(t), \Delta r$ is the range resolution in meters, and $c_{\text {ice }}$ is the bulk sound speed in the ice outside of the skeletal layer.

Elsewhere, the value of $g_{j}(t)$ equals either zero or one to represent the presence or absence of an interface. The location of these values is determined by the travel time to the interfaces by combining the sound speed in water with the sound speed in ice as determined by the modeled $h_{\text {ice }}$ and the sound speed profile in Eq. (1). This approach neglects multiple reflections given that most of the energy is transmitted across the water-ice interface. The total time series

$$
\hat{x}_{\text {total }}(t)=\sum_{j=1}^{n}\left|\hat{x}_{\mathrm{pc}, \mathrm{j}}(t) \otimes g_{j}(t)\right|^{2}
$$

is the incoherent summation of the pulse compressed time series from the different backscattering sources.

Each term is calculated independently and the summation leads to total pulse-compressed time series $\hat{x}_{\text {total }}(t)$.
Results are presented as the logarithmic envelope (E) of the pulse-compressed time series. $\mathrm{E}$, in units of $\mathrm{dB}$ re $\mathrm{p}_{\mathrm{o}}^{2}$, is described by

$$
\mathrm{E}(t)=10 \log _{10}\left(\hat{x}_{\text {total }}(t)\right) .
$$

As defined, E scales with the range but the amplitude is otherwise fixed by the transducer (beamwidth), transmit bandwidth, and ice properties. In the case of experimental data, E is normalized by the amplitude at the water-ice interface.

\section{RESULTS AND PREDICTIONS}

The modeled or measured backscatter from both interfaces is strongly dependent on the transmitted frequency due to the sound speed profile, roughness of the ice, and the backscattering and attenuation within the ice. Bassett et al. (2016) show broadband measurements of backscattering from the water-ice interface as a function of frequency. At frequencies greater than $200 \mathrm{kHz}$, backscatter becomes highly variable and at even higher frequencies penetration into the ice is limited by the scattering and high attenuation rates. Low SNRs may have been a limiting factor in Bassett et al. (2016) at the highest frequencies. These results, which are derived from the same data presented here, show that at the lowest frequencies measured $(75-130 \mathrm{kHz})$ echoes from both the water-ice and ice-air interfaces were observed with ice thicknesses up to approximately $80 \mathrm{~cm}$. Figure 5 includes examples of the Hann-tapered envelopes showing both interfaces for multiple ice thicknesses. The $y$-axes in Fig. 5 and elsewhere are shifted so that the time delay is always $0 \mathrm{~ms}$ at the water-ice interface. Echoes from the ice-air interface in these examples also show the amplitude decreases due to attenuation in the ice. Figure 5(c) includes a comparison between the ice thicknesses measured by the ice cores and the ice thicknesses as inferred from the time delay between the echoes. As expected, the measured ice draft is always less than the length of the ice core (Fig. 6). However, when the acoustically measured ice draft plus the measured freeboard are compared to the inferred thickness and the results agree well. A total of 11 samples were available where
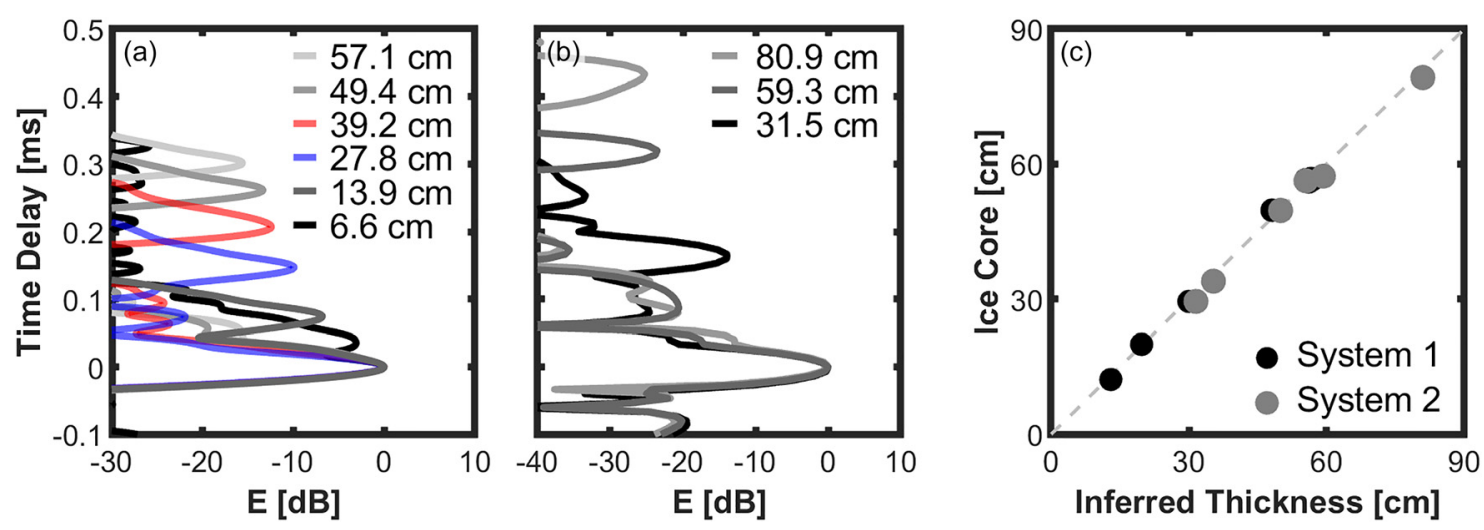

FIG. 5. (Color online) (a) Envelopes from System 2 experimental data for different ice thicknesses. (b) Envelopes from System 1. (c) A comparison between the thickness of ice cores and the inferred thickness using Eq. (1). Note that the acoustic measurements and cores were taken at similar times but the locations were not the same in order to maintain the integrity of the ice for future samples. 


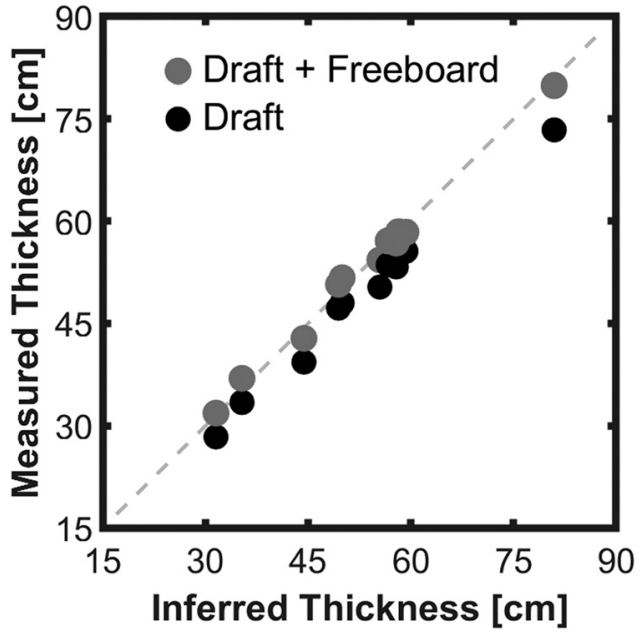

FIG. 6. Ice thicknesses measured from ice draft plus freeboard versus the inferred ice thicknesses. Good agreement between the methods when including the draft and freeboard suggests the method adequately captures the total ice thickness and hence, the ice freeboard (thickness minus draft) can be resolved.

average ice core thicknesses and freeboards could be compared to inferred ice thicknesses and drafts. Measured freeboards during the experiment ranged from 2 to $7 \mathrm{~cm}$. The mean residual [Eq. (3)] was $0.02 \mathrm{~cm}$ and the standard deviation was $1.3 \mathrm{~cm}$. The maximum measured $\left|h_{\text {res }}\right|$ value was approximately $1.7 \mathrm{~cm}$. The small mean suggests the inferred thickness using the sound speed profile performs well. Uncertainty in individual ice core measurements was $\pm 0.5 \mathrm{~cm}$ and variability in measured ice core lengths from samples taken at the same time but different locations in the tank were on the order of $1-2 \mathrm{~cm}$. No co-located acoustic and physical measurements are available due to the destructive nature of the physical sampling and a desire to maintain the ice structure for future sampling.

Sea ice microstructure is sensitive to the ambient air temperature. The inferences in Fig. 5 do not account for a temperature-dependent sound speed profile although the ambient conditions in the tank were consistent with those under which the sound speed profile was derived. Figure 7 shows the percentage differences that would be obtained if applying Eq. (1) as opposed to Williams and Francois [1992, Eq. (25)], which accounts for both the ice thickness and air temperature. For warm ice temperatures (approaching $0^{\circ} \mathrm{C}$ ), Eq. (1) over-predicts ice thickness by assuming the sound speed in the ice is considerably higher than that of higher porosity ice. On the other hand, agreement improves between the methods as the temperatures decrease or as the ice sheet gets thicker. For ice thicknesses in excess of $50 \mathrm{~cm}$ and air temperatures of less than $-10^{\circ} \mathrm{C}$, the methods agree to within approximately 5\%. Agreement is poor for ice thicknesses less than $20 \mathrm{~cm}$ when the different treatment of the skeletal layer causes larger differences in the average sound speed within the ice.

The inferences of ice thickness from under-ice backscattering measurements rely on clearly identifying both interfaces. Appropriate transmit signals strike a balance

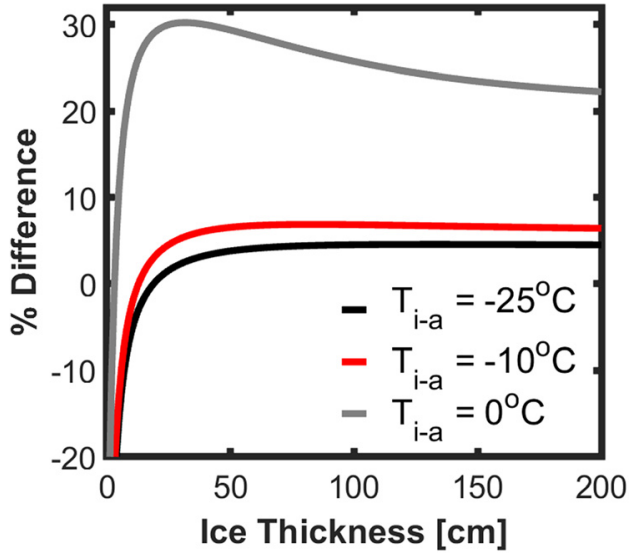

FIG. 7. (Color online) The percent differences in inferred ice thickness versus actual ice thickness that would result from using Eq. (1) and Williams and Francois [1992, Eq. (25)]. Positive values are associated with Eq. (1) yielding greater ice thicknesses. Larger differences for thinner layers of ice are driven by the treatment of the skeletal layer. At higher temperatures, differences are the result of a higher porosity (lower sound speed) of the ice, which is accounted for by Williams and Francois [1992, Eq. (25)]. These results highlight the importance of temperature and accounting for the skeletal layer, especially for relatively thin ice and warm conditions.

between the range resolution (bandwidth), backscattering from the water-ice interface, attenuation within the ice, backscattering from microstructure, and the size of the transducer. Figure 8 includes measurements and modeled time-domain results for the $256 \mu$ s pulse durations with a Hann-tapered $75-130 \mathrm{kHz}$ LFM signal. In general, when using untapered transmit signals sidelobes would extend a range of $c \tau_{t} / 2$ from the interface, where $c$ and $\tau_{t}$ are the relevant sound speeds and pulse durations, respectively. Even with the short pulse duration the sidelobes overlap, thereby demonstrating the value of tapering in this application.

When including volume scattering, adequately detecting the ice-air interface and constraining the relative arrival time of the echo requires that the SNR is sufficiently large. Although temporal and frequency-domain results are directly related, backscattering curves are more easily

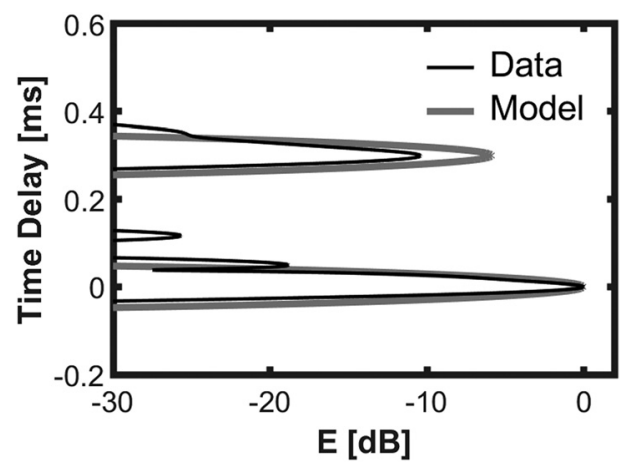

FIG. 8. A comparison between data (System 2) with a Hann-tapered LFM chirp from 75 to $130 \mathrm{kHz}$ and modeled results for the same signal. The measured and inferred ice thicknesses are $56 \mathrm{~cm}$. The envelopes are normalized by their values at the water-ice interface. Volume scattering from bubbles is not included because no measurements of bubble size or bubble density are available and sampled volumes were small. 


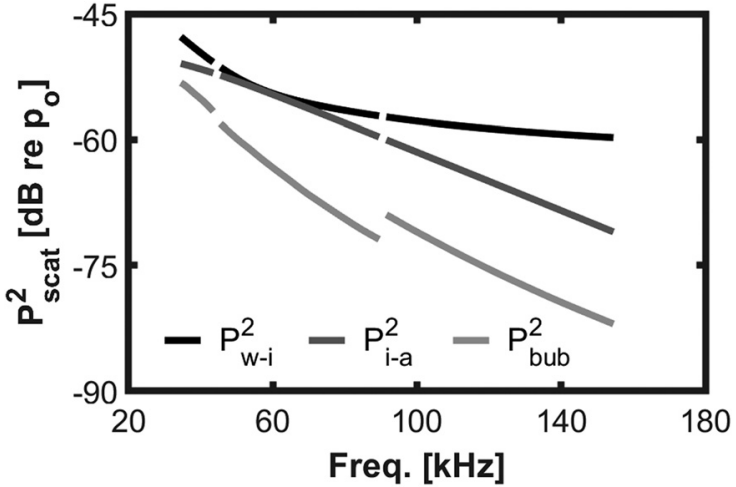

FIG. 9. Frequency-domain backscattering curves calculated according to Eqs. (8), (9), and (12) for a range of $20 \mathrm{~m}$ and an ice thickness of $120 \mathrm{~cm}$. The volume scattering curves account for the frequency-dependent sampled volume and is calculated at the mid-point of the ice $(60 \mathrm{~cm})$.

interpreted in the frequency domain. Figure 9 shows modeled $P_{w-i}^{2}, P_{i-a}^{2}$, and $P_{b u b}^{2}$ curves at a range of $20 \mathrm{~m}$ with an ice thickness of $120 \mathrm{~cm}$. Each of the three channels exhibits different relative amplitudes due to the differences in sampled volume, attenuation, and water-ice interface reflection coefficients. In practice, the amplitudes of all curves shift with range and the relative amplitudes of the volume scattering and ice-air interface terms shift with the ice thickness due to attenuation. Notably, the amplitudes of the scattering from the bubbles and the ice-air interface are similar at lower frequencies due to a larger volume and higher individual bubble target strengths. Figure 9 also supports the interpretation of the temporal domain model in that when the range and ice thicknesses are the same the average values of $P^{2}$ from these curves are consistent with the amplitudes of the envelopes presented in the temporal domain models.

Temporal domain results, including the contributions from the different scattering and reflection sources, for a $1 \mathrm{~m}$ ice thickness at a range of $20 \mathrm{~m}$ using a Hann-tapered $45-90 \mathrm{kHz}$ signal are included in Fig. 10. In this case, both interfaces are easily identifiable and the ice-air interface has a SNR, where the backscattering from the bubbles is the noise, of approximately $20 \mathrm{~dB}$. Since the relative amplitudes

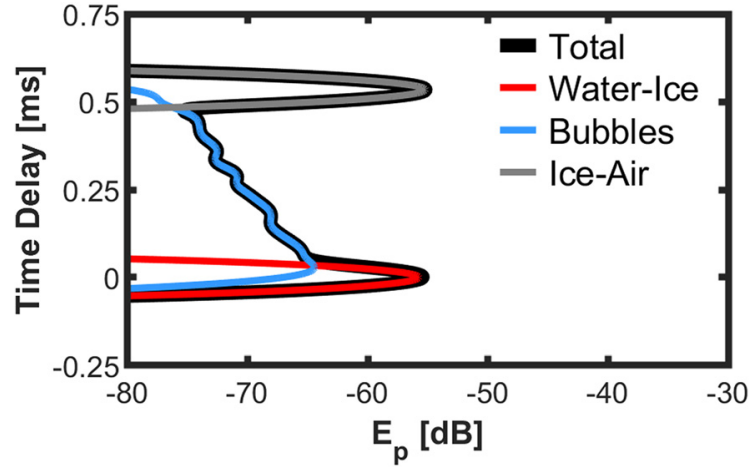

FIG. 10. (Color online) Model results $(45-90 \mathrm{kHz})$ for an ice thickness of $1 \mathrm{~m}$ showing the contributions from the water-ice interface, bubbles, and the ice-air interface. The modeled range to the water-ice interface is $20 \mathrm{~m}$.

of these interfaces scale primarily with the attenuation (neglecting differences due to the effects of refraction within the ice) sufficient SNRs for ice thickness inference are expected over a broad range of first-year ice thicknesses. Unlike the water-ice interface, which has a frequencydependent reflection coefficient but no dependence on the ice thickness, both the bubble scattering and ice-air reflection terms are dependent on the bandwidth of the transmit signal and the ice thickness.

Modeled envelopes for Hann-tapered signals using all three bandwidths and ice thicknesses from 15 to $120 \mathrm{~cm}$ and shown in Fig. 11. For $34-45 \mathrm{kHz}$, unique echoes from the interfaces are not easily identified for ice thicknesses less than $50 \mathrm{~cm}$ due to the poor range resolution and SNRs relative to the volume scattering. The $45-90$ and $90-160 \mathrm{kHz}$ signals include unique echoes for all modeled ranges but might be limited in practice to thicknesses greater than 20-30 cm to have sufficient SNRs for reliable detection. In contrast to the data in Fig. 5, for relatively thin ice layers, the model suggests reflections from the ice-air interface are larger than echoes from the water-ice interfaces. The inclusion of the index of refraction term in the range to the iceair interface accounts for this difference between the modeled and measured data. Effective transmission of energy
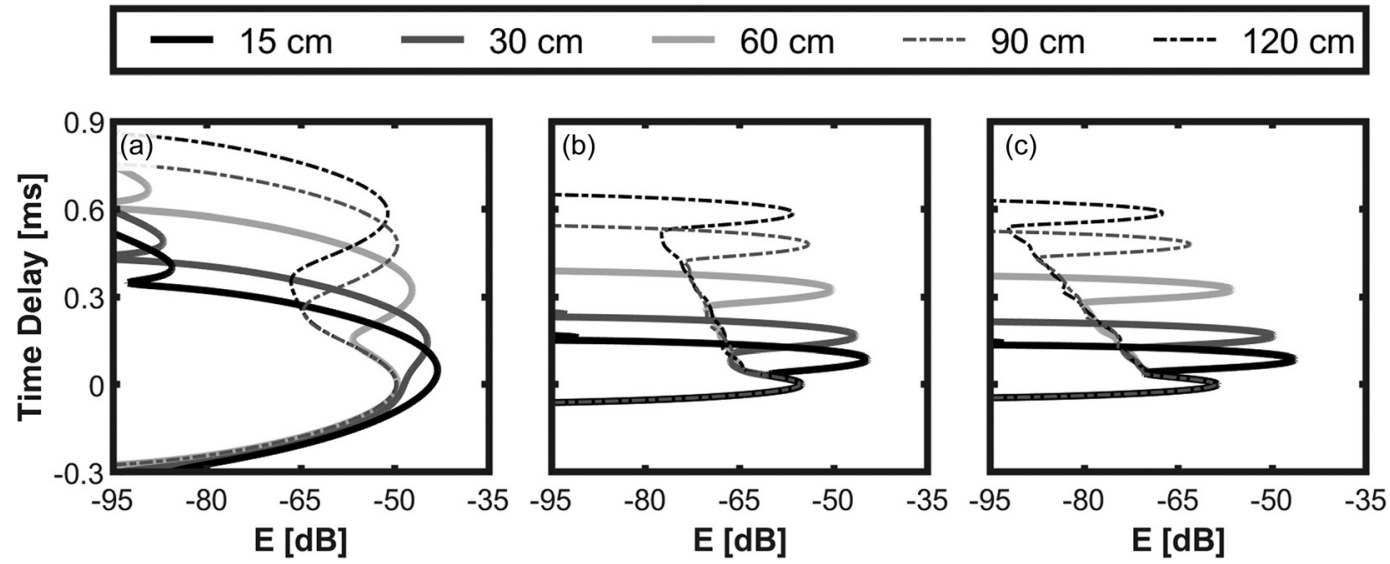

FIG. 11. Model results for three bandwidths using $7^{\circ}$ beamwidths at the nominal frequency (Table I) and a range of $20 \mathrm{~m}$ to the water-ice interface. (a) $34-45 \mathrm{kHz}$. (b) $45-90 \mathrm{kHz}$. (c) $95-155 \mathrm{kHz}$. 
across the water-ice interface combined with high reflection coefficients at the ice-air interface suggests that under the modeled conditions losses in the ice should not prohibit penetration through thicknesses associated with first-year sea ice. Relative amplitudes of the interfaces are similar over a range of ice thicknesses. Therefore, less aggressively tapered transmit signals may not interfere with ice thickness inferences while correspondingly improving bandwidth and the range resolution.

\section{DISCUSSION}

High-frequency, broadband acoustic backscattering at normal incidence has been shown to be an effective method for estimating the thickness of a growing congelation ice sheet under laboratory conditions. Thickness estimates based on the time delay between the water-ice and ice-air interfaces agree well with thicknesses obtained from ice cores. Estimates based on the ice draft alone (Fig. 6) underestimate the ice thicknesses because they do not account for the freeboard. Inferred ice thicknesses using this approach agreed well with the sum of the acoustically measured ice draft plus the freeboard measured from the ice cores. The good agreement between the different methods suggests the potential to decouple estimates of ice thickness from measurements of the sonar depth, oceanic sound speed profile, or knowledge of sea surface height from leads. Furthermore, direct inference by the time delay estimates the total ice thickness so measurements of ice draft from the same data could be used to calculate freeboard. That the measured thickness was consistently greater than the draft suggests that, despite the fact that it is small relative to total thickness, freeboard may be detectable provided sound speed of the ice is well constrained. In the case of thin ice sheets ( $h_{\text {ice }}<20 \mathrm{~cm}$ ), failing to account for the non-uniform sound speed profile of the skeletal layer is likely to result in underestimates of the ice thickness. For thick ice sheets applying a uniform sound speed that is consistent with the bulk sound speed of the ice outside of the skeletal layer results in better agreement because the travel time is dominated by the higher bulk sound speed outside of the skeletal layer.

The model presented here is based on measurements performed in other in situ studies of sea ice and the good agreement with measurements, both in terms of the amplitudes of the pulse-compressed data and the time delays between the interfaces, suggests a good parameterization of the model. Nonetheless, most of the variables are calculated based on relatively few publications representing a limited number of ambient conditions. To apply such a technique in situ, representative sea ice properties including the bulk sound speed, attenuation, and the volumes/distributions of important scatterers should be measured over a broader range of conditions, including seasonal variations. By better constraining individual parameters it may also be possible to invert acoustic data to improve estimates of the other parameters included in this model.
Here the modeled bubble distributions are based on Light et al. (2003). Lower bubble densities that corresponded with larger bubble sizes were reported by Grenfell (1983) for ice from the Beaufort Sea. Light et al. (2003), however, noted that larger bubble sizes reported by Grenfell (1983) were attributable to the near-melting point condition of the ice. This study also lacked the image quality to determine whether these larger bubbles were restricted to brine pockets or were also present within the ice matrix where boundary conditions would suppress bubble resonance thereby altering target strength curves. Parameterization of the model using Grenfell (1983), assuming larger bubbles are only present within brine channels, results in larger volume backscattering coefficients than shown in Fig. 4(b). These are driven by the larger target strengths of individual bubbles across the relevant bandwidth. When applied to the model this shifts the resulting envelopes upward, reducing the SNRs between the interfaces and volume scattering. In fact, for this case (not shown), curves similar to Fig. 9 show volume backscattering that exceeds interface reflections below approximately $55 \mathrm{kHz}$, which could be a limiting factor for this technique. Lacking additional studies it is not possible to determine how representative these reported bubble distributions may be and more work on the subject is necessary to further constrain models and interpretation.

It is likely that there are significant changes in backscatter from undeformed sea ice during the early growth stages and during melt-out. When sea ice is melting the porosity is much higher than during ice growth (Petrich and Eicken, 2009). Furthermore, the temperature gradient in the ice will change and may no longer be linear. These factors likely result in changes to the sound speed profile, attenuation, and scattering from microstructure, although the extent to which these factors would affect ice thickness measurements is unknown and should be the focus of future work. Nonetheless, the basic expectation would be that higher temperatures would reduce the bulk sound speed, increase the attenuation, and alter losses in the skeletal layer. These changes would be driven by an increase in porosity within the ice and structural changes to the skeletal layer. Measurements of the temperature dependence of the sound speed of fresh, bubble-free ice have been reported (Vogt et al., 2008, and references therein) and agree with the expected trend, but are not applicable due to the differences in microstructure.

The disappearance of the skeletal layer during the boreal summer is likely to result in significant changes to the water-ice reflection coefficient thereby reducing the transmission of energy across the interface. This scenario is not considered here but could be studied using laboratory experiments. Regardless, the amount of energy reflected from the interfaces in Fig. 11 overlaps with or is stronger than individual targets in other common echosounder applications. For example, echosounders in the frequency ranges applied here are regularly used to survey fishes with and without gas bladders. A range of representative target strength values for individual fish in these applications is 
from -60 to $-30 \mathrm{~dB}$ re $1 \mathrm{~m}^{2}$ (Gauthier and Horne, 2004) and individuals can be identified at ranges in excess of $100 \mathrm{~m}$ at the frequencies discussed here. Even after accounting for the considerable losses within the ice the modeled reflections are comparable to or exceed these levels due to the relatively large reflection coefficients. As a result, differences in scattering due to structural changes at the water-ice interface that would affect the amplitude of all of the echoes would still result in scattering levels that fall well within the dynamic range of common systems. Seasonal variability in ice first-year ice, therefore, will not necessarily limit the use of this technique unless bubbles densities or volumes are considerably higher. However, better constrained properties accounting for the difference in ice structure would need to be applied.

As parameterized, the model suggests that the best frequencies for directly measuring sea ice thickness require a delicate balance between competing factors. Losses due to attenuation are not a limitation in cold temperatures, although they may be important under warmer conditions. While attenuation can be reduced by using lower frequencies, lower frequency broadband transducers cannot, in general, transmit as much bandwidth and therefore have inherently lower temporal resolutions. In contrast, published bubble distributions for first-year ice suggest increasing levels of backscattering at lower frequencies, suggesting higher frequencies would be more favorable. At frequencies in excess of $200 \mathrm{kHz}$, the backscatter is expected to become less coherent due to the roughness of the skeletal layer, thereby increasing the complexity of the echoes. Large-scale undulations or roughness would also complicate ice thickness measurements and the impact could be limited by using narrow beams. The physical factors and modeled results suggest that frequencies between $50-200 \mathrm{kHz}$ are most appropriate for the application. For a piston-like transducer of a given size, a higher operational frequency will result in a narrower beamwidth. Therefore, operating at the higher end of the aforementioned frequency range may be advantageous for a variety of deployment platforms.

Another practical consideration and potential limitation in identifying the echo from the ice-air interface is delayed echo interference from the water-ice interface due to transducer sidelobes. Whether or not this interference causes problems for the methodology is dependent on a number of factors including the range to the water-ice interface, ice thickness, and sidelobe geometry and amplitude. These contributions have not been modeled here but their relative importance can be considered using available information. Take, for example, a transducer with properties similar to the $70 \mathrm{kHz}$ transducer modeled here. Typical sidelobe amplitudes are approximately $25 \mathrm{~dB}$ lower than the main lobe and the first sidelobe is at approximately 20 degrees. Furthermore, at modeled frequencies for "smooth ice" the water-ice interface is relatively smooth, resulting in coherent echoes whose intensities are about $15 \mathrm{~dB}$ lower than at normal incidence (Bassett et al., 2017; Tang et al., 2015).
At $20 \mathrm{~m}$ the time delay for two-way travel to the water-ice interface is approximately $1.1 \mathrm{~ms}$. This corresponds roughly to the time delay between the ice-air interface for an ice thickness of $2 \mathrm{~m}$ and will not interfere with the echo for smaller ice thicknesses. Under rough ice or with different transducer geometries sidelobes could interfere with these methods. Nonetheless, transducer specifications and available literature can be used to identify cases when sidelobes could be a limiting factor and this should be taken into account when designing experiments.

An important factor not accounted for in this model is potential scattering from other inhomogeneities within sea ice. If discontinuities resulting in large variations in sound speed or density exist within the ice they could scatter a sufficient amount of energy to make it difficult to apply this method. For example, even level sea ice can be composed of multiple layers due to rafting of thin ice, and this could affect scattering properties or produce internal reflections. Likewise, the large-scale roughness of the water-ice interface or ice-air interface over the ensonified area could also confound measurements. Further studies should be performed at relevant ranges to further investigate the potential performance of this approach in situ, specifically in cases with deformed ice and non-normal incidence angles. Similarly, modeling efforts can be undertaken to specifically address the limitations under more complicated conditions. Backscatter from brine channels could also have an impact on measurements, especially when using higher frequencies at warmer temperatures when the porosity is higher and the size of brine inclusions increases.

While the results presented here suggest the possibility of remotely inferring sea ice thickness using the temporal domain scattering time series from broadband sonars, the application of sound speed values available from the literature would lead to unknown errors in the inferred ice thickness and are the most important under-constrained parameter in the model. In fact, it is the only parameter that is used to infer the thickness while the other terms simply affect the feasibility of the method. Additional research supporting this approach should focus on the sound speed of ice under all conditions.

The application of acoustic backscattering for the direct inference of multi-year ice has not been considered and is subject to different challenges and uncertainties. In multiyear hummocked ice, bubble densities in the upper ice can be very high and bubbles can be large (Perovich and Gow, 1996); thus, it is possible that the SNR may be too low to detect ice thickness for some ice types. Likewise, rafting of ice can result in large air pockets and additional discontinuities within the ice pack that poses challenges for acoustic transmission through the ice and interpretation of the complex scattering. In addition to these challenges, multi-year ice has lower salinity and the acoustic properties will not match those of first-year ice. Therefore, while penetration through multi-year ice may be possible using a similar approach, the impact of different scattering sources and acoustic properties must be considered and relatively little 
supporting information is currently available in the literature.

Any attempts to apply this method in future studies of ice thickness may also overlap well with other research objectives. For example, the frequency range from 45 to $160 \mathrm{kHz}$ conveniently aids in the classification of biological taxa (Bassett et al., 2017; Jech et al., 2017; Ross et al., 2013). As a result, moorings targeting biological scattering under ice could, under the right circumstances, also be used to estimate ice thicknesses. Conveniently, the relatively high frequency ranges that are ideal for this application result in rather small transducers that can be easily deployed on moorings and remotely-operated and autonomous vehicles. These factors further support ice thickness inferences as an additional data product without interfering with traditional approaches or other research goals.

\section{CONCLUSIONS}

Using measurements of broadband acoustic backscattering from laboratory-grown sea ice and a model capturing the dominant scattering mechanism within the sea ice, the feasibility of directly inferring ice thickness based on the echoes from the water-ice and ice-air interfaces has been demonstrated. Good agreement is shown between ice thicknesses derived from ice cores and those inferred only from the time delay between the interfaces. The amplitudes of the observed scattering from the interfaces in the experimental data and models compare favorably, suggesting a wellparameterized model for the conditions. Modeling results between 34 and $155 \mathrm{kHz}$ suggest that frequencies between 45 and $155 \mathrm{kHz}$ strike a good balance between the competing frequency-dependent parameters that include reflection coefficients from the interfaces, attenuation in the skeletal layer and ice, scattering from bubbles, and the range resolution. Ice microstructure and attenuation impose limitations on this technique at higher frequencies. Broadband transducers in optimal frequency ranges are relatively small and commercially available. One advantage of this method is that it requires no information about the range to the icewater interface or the sound speed in the water. Although further research is needed to establish the feasibility to infer ice thickness for all ice types (e.g., multi-year, deformed, or very bubbly ice), these measurements could supplement traditional acoustic measurements of ice draft, as the frequency range of the proposed broadband signals does not interfere with traditional ice draft measurements. Thus, this technique could provide an additional constraint on thickness, to improve ice draft accuracy, identify variations in ice type from variations in internal scattering signatures, or, if sound speed can be constrained well enough, estimate the ice freeboard. While the models suggest this approach could be useful in situ, more measurements of these properties that capture seasonal variability in ice sound speed profiles and attenuation would reduce the errors and uncertainties in the models.

\section{ACKNOWLEDGMENTS}

The authors would like to thank the staff at CRREL, especially Leonard Zablinksi, Ben Winn, Jesse Stanley, Nathan Lamie, Zoe Courville, and Bruce Elder for their project support. Discussions with DJ Tang were helpful throughout the project. Funding for laboratory work used to support this research was provided by the International Oil and Gas Producers Arctic Oil Spill Technology Joint Industry Programme under contract 28_13-14.

${ }^{1}$ See supplementary material at https://doi.org/10.1121/10.0000619 for derivation of the correction accounting for refraction within the ice.

Bassett, C., De Robertis, A., and Wilson, C. D. (2017). "Broadband echosounder measurements of the frequency response of fishes and euphausiids in the Gulf of Alaska,” ICES J. Mar. Sci. 75(3), 1131-1142.

Bassett, C., Lavery, A. C., Maksym, T., and Wilkinson, J. (2015). "Laboratory measurements of high-frequency, acoustic broadband backscattering from sea ice and crude oil," J. Acoust. Soc. Am. 137(1), EL32-EL38.

Bassett, C., Lavery, A. C., Maksym, T., and Wilkinson, J. (2016). "Broadband acoustic backscatter from crude oil under laboratory-grown sea ice," J. Acoust. Soc. Am. 140(4), 2274-2287.

Behrendt, A., Dierking, W., Fahrbach, E., and Witte, H. (2013). "Sea ice draft in the Weddell Sea, measured by upward looking sonars," Earth Syst. Sci. Data 5, 209-226.

Biot, M. (1956a). "Theory of propagation of eleastic waves in a fluidsaturated porous solid: Low-frequency range," J. Acoust. Soc. Am. 28, $168-178$.

Biot, M. (1956b). "Theory of propagation of elastic waves in a fluidsaturated porous solid: Higher frequency range," J. Acoust. Soc. Am. 28, 179-191.

Brekhovskikh, L. M., and O. A. Godin (1990). Acoustics of Layered Media I, Springer Series on Wave Phenomena (Springer-Verlag, Berlin), pp. 31-33.

Capelli, A., Kapil, J. C., Reiweger, I., Or, D., and Schweizer, J. (2016). "Speed and attenuation of acoustic waves in snow: Laboratory experiments and modeling with Biot's theorys," Cold Reg. Res. Technol. 125, $1-11$.

Chen, C. T., and Millero, F. J. (1977). "Speed of sound in seawater at high pressures," J. Acoust. Soc. Am. 62(5), 1129-1135.

Chu, D., and Stanton, T. (1998). "Application of pulse compression techniques to broadband acoustic scattering by live individual zooplankton," J. Acoust. Soc. Am. 104(1), 39-55.

Courville, Z., Lieb-Lappen, R., Claffey, K., and Elder, B. (2017). "Investigations of skeletal layer microstructure in the context of remote sensing of oil in sea ice," in Proceedings of the International Oil Spill Conference, May 15-18, Los Angeles, CA, pp. 2237-2255.

Eicken, H., Bluhm, B., Collins, R., Haas, C., Ingham, M., Gradinger, R., Mahoney, A., Nicolaus, M., and Perovich, D. (2014). Field Techniques for Sea-Ice Research (University of Chicago Press, Chicago, IL), p. 368.

Forsberg, R., and Skourup, H. (2005). "Arctic ocean gravity, geoid and seaice freeboard heights from ICESat and GRACE," Geophys. Res. Lett. 32, L21502, https://doi.org/10.1029/2005GL023711.

Francois, R., and Garrison, G. (1982a). "Sound absorption based on ocean measurements: Part I: Pure water and magnesium sulfate contributions," J. Acoust. Soc. Am. 72(3), 896-907.

Francois, R., and Garrison, G. (1982b). "Sound absorption based on ocean measurements. Part II: Boric acid contribution and equation for total absorption," J. Acoust. Soc. Am. 72(6),1879-1890.

Galley, R., Trachtenberg, M., Langlois, A., Barber, D., and Shafai, L. (2009). "Observations of geophysical and dielectric properties and ground penetrating radar signatures for discrimination of snow, sea ice and freshwater ice thickness," Cold Reg. Sci. Technol. 57(1), 29-38.

Garrison, G., Francois, R., and Wen, T. (1991). "Acoustic reflections from Arctic ice at 15-300 kHz,” J. Acoust. Soc. Am. 90(2), 973-984. 
Gauthier, S., and Horne, J. K. (2004). "Acoustic characteristics of forage fish species in the Gulf of Alaska and Bering Sea based on Kirchhoffapproximation models," Can. J. Fish. Aquat. Sci. 61, 1839-1850.

Gavrilo, V., and Gaitskhoki, B. (1971). "The statistics of air inclusions in ice," in The Physics of Ice, edited by V. V. Bogorodskii (National Science Foundation, Washington, DC), pp. 125-128.

Grenfell, T. C. (1983). "A theoretical model of the optical properties of sea ice in the visible and near infrared," J. Geophys. Res. Oceans 88(C14), 9723-9735, https://doi.org/10.1029/JC088iC14p09723.

Haas, C., Gerland, S., Eicken, H., and Miller, H. (1997). "Comparison of sea ice thickness measurements under summer and winter conditions in the Arctic using a small electromagnetic induction device," Geophysics 62(3), 749-757.

Jech, J. M., Lawson, G., and Lavery, A. C. (2017). "Wideband (15-260 $\mathrm{kHz}$ ) acoustic volume backscattering spectra of Northern krill (Meganyctiphanes norvegica) and butterfish (Oeorilus triacanthus)," ICES J. Mar. Sci. 74(8), 2249-2261.

Kwok, R., Cunningham, G., Zwally, H., and Yi, D. (2007). "Ice, cloud, and land elevation satellite (ICESat) over Arctic sea ice: Retreival of freeboard," J. Geophys. Res. Oceans 112, C12013, https://doi.org/10.1029/ 2006JC003978.

Kwok, R., and Rothrock, D. (2009). "Decline in Arctic sea ice thickness from submarine and ICESat records: 1958-2008," Geophys. Res. Lett. 36, L15501, https://doi.org/10.1029/2009GL039035.

Langleben, M. (1969). "Attenuation of sound in sea ice, 10-500 kHz," J. Glaciol. 54(8), 399-406.

Lavery, A., Bassett, C., Lawson, G., and Jech, J. (2017). "Exploiting signal processing approaches from broadband echosounders," ICES J. Mar. Sci. 74(8), 2262-2275

Lavery, A., Chu, D., and Moum, J. (2010). "Measurements of acoustic scattering from zooplankton and oceanic microstructure using a broadband echosounder," ICES J. Mar. Sci. 67, 379-394.

Laxon, S., Peacock, N., and Smith, D. (2003). "High interannual variability of sea ice thickness in the Arctic region," Nature 425(6961), 947-950.

Light, B., Maykut, G., and Grenfell, T. (2003). "Effects of temperature on the microstructure of first-year Arctic sea ice," J. Geophys. Res. Oceans 108(C2), 3051, https://doi.org/10.1029/2001JC000887.

Lyons, W. (1961). "Ocean and sea-ice research in the Arctic ocean using submarines," Trans. N.Y. Acad. Sci. Ser. 23(8), 662-674.

Medwin, H., and Clay, C. S. (1998). Fundamentals of Acoustics Oceanography (Academic Press, Boston, MA), pp. 138-141; 290-291.

Melling, H. (1998). "Sound scattering from sea ice: Aspects relevant to icedraft profiling by sonar,” J. Atmos. Ocean. Technol. 15(4), 1023-1034.

Mourad, P., and Williams, K. (1993). "Near-normal incidence scattering from rough, finite surfaces: Kirchoff theory and data comparison for Arctic sea ice," J. Acoust. Soc. Am. 94(3), 1584-1597.

Nayar, K. G., Sharqawy, M. H., Banchik, L. D., and Lienhard, J. H. (2016). "Thermophysical properties of seawater: A review and new correlations that include pressure dependence," Desalination 390, 1-24.

Pegau, S., Garron, J., and Zabilansky, L. (2016). "Detection of oilon-inand-under ice," Arctic Oil Spill Response Technology Joint Industry Program (JIP) Report, Final Report 5.3.

Pegau, S., Garron, J., Zabilansky, L., Bassett, C., Bello, J., Bradford, J., Carns, R., Courville, Z., Eicken, H., Elder, B., Eriksen, P., Lavery, A., Light, B., Maksym, T., Marshall, H., Oggier, M., Perovich, D., Pacwiardowski, P., Singh, H., Tang, D., Wiggins, C., and Wilkinson, J. (2017). "Detection of oil in and under ice," in Proceedings of the International Oil Spill Conference, May 15-18, Los Angeles, CA, pp. 1857-1876.

Perovich, D., and Gow, A. (1991). "A statistical description of the microstructure of sea ice inclusions," J. Geophys. Res. 96(C9), 16943-16953, https://doi.org/10.1029/91JC01594.
Perovich, D., and Gow, A. (1996). "A quantitative description of the microstructure of sea ice inclusions,” J. Geophys. Res. 101(C8), 18327-18343, https://doi.org//10.1029/96C01688.

Petrich, C., and Eicken, H. (2009). "Growth, structure and properties of sea ice," in Sea Ice, edited by D. N. Thomas and G. S. Dieckmann (WileyBlackwell, Oxford, UK).

Ross, T., Keister, J. E., and Lara-Lopez, A. (2013). "On the use of highfrequency broadband sonar to classify biological scattering layers from a cabled observatory in Saanich Inlet, British Columbia," Methods Oceanagr. 5, 19-38.

Rothrock, D., and Wensnahan, M. (2007). "The accuracy of sea ice drafts measured from U.S. Navy submarines,” J. Atmos. Ocean. Technol. 24, 1936-1949.

Rothrock, D., Yu, Y., and Maykut, G. A. (1999). "Thinning of the Arctic sea-ice cover," Geophys. Res. Lett. 26(23), 3469-3472, https://doi.org/ 10.1029/1999GL010863.

Schwarz, J., and Weeks, W. F. (1979). "Engineering properties of sea ice," J. Glaciol. 19(81), 499-531.

Sharqawy, M. H., Lienhard, J. H., and Zubair, S. M. (2010). "Thermophysical properties of seawater: A review of existing correlations and data," Desalination Water Treat. 16, 354-380.

Stanton, T. (2012). "30 years of advances in active bioacoustics: A personal perspective," Methods Oceanagr. 1-2, 49-77.

Stanton, T. K., Jezek, K. C., and Gow, A. J. (1986). “Acoustical reflection and scattering from the underside of laboratory grown sea ice: Measurements and predictions," J. Acoust. Soc. Am. 80(5), 1486-1494.

Tang, D., Jackson, D., Bassett, C., and Lavery, A. C. (2015). "Modeling high-frequency acoustic backscatter for remote sensing of oil under sea ice and oil encapsulated in sea ice," J. Acoust. Soc. Am. 138(3), 1744.

Timco, T. G. W., and Frederking, R. M. W. (1996). “A review of sea ice density," Cold Reg. Sci. Technol. 24(1), 1-6.

Turin, G. (1960). "An introduction to matched filters," IRE Trans. Inf. Theory 6(3), 311-329.

Vagle, S., and Farmer, D. (1992). "The measurement of bubble-size distributions by acoustical backscatter," J. Atmos. Ocean. Technol. 9, 630-644.

Vogt, C., Laihem, K., and Wiebusch, C. (2008). "Speed of sound in bubblefree ice," J. Acoust. Soc. Am. 124(6), 3613-3618.

Wadhams, P. (2000). Ice in the Ocean (Gordon and Breach Science Publishers, Amsterdam, the Netherlands), p. 351.

Weeks, W. (2010). On Sea Ice (University of Alaska Press, Fairbanks, AK).

Wen, T., Garrison, G., Francois, R., Stein, P., and Felton, W. (1991). "Sound speed, reflectivity, and absorption measurements for Arctic ice in 1988,” Applied Physics Laboratory Report No. APL-UW TR 9005.

Wilkinson, J., Wadhams, P., and Hughes, N. (2007a). "Modelling the spread of oil under fast sea ice using three-dimensional multibeam sonar data," Geophys. Res. Lett. 34, L22506, https://doi.org/10.1029/ 2007 GL031754.

Wilkinson, J., Wadhams, P., and Hughes, N. (2007b). A Review of the Use of Sonar on Underwater Vehicles to Obtain Information on Sea Ice Draft, EUR22416 (European Comission, Brussels, Climate Change and Natural Hazards Series), pp. 30-45.

Williams, K., and Francois, R. (1992). "Sea ice elastic moduli: Determination of Biot parameters using in-field velocity measurements," J. Acoust. Soc. Am. 91(5), 2627-2636.

Williams, K., Garrison, G., and Mourad, P. (1992). "Experiment examination of growing and newly submerged sea ice including acoustic probing of the skeletal layer," J. Acoust. Soc. Am. 92(4), 2075-2092.

Williams, G., Maksym, T., Wilkinson, J., Kunz, C., Kimball, P., and Singh, H. (2015). "Thick and deformed Antarctic sea ice mapped with autonomous underwater vehicles," Nature Geosci. 8, 61-67.

Winebrenner, D. (1992). "Acoustic backscattering from sea ice at high frequencies," Applied Physics Laboratory Report No. APL-UW TR 9017. 